\title{
Social Life of Senior Citizens: A Review of Therapeutic Effects of Gardening for Wellbeing in Urban Nepal
}

\author{
Gita Khadka \\ Singhania University, Rajasthan, INDIA \\ School of Applied and Social Science \\ Megh Raj Dangal \\ Kathmandu University, School of Arts, NEPAL
}

Received: 5 March 2021 • Accepted: 29 June 2021 • Published Online: 31 July 2021

\begin{abstract}
This paper provides the insights for a better understanding of individual, familiar, and social factors of loneliness that influence wellbeing of people in later life. The review offers a thematic analysis on loneliness in elderly people and the therapeutic effects of gardening activities for healthy ageing. Five key themes related to loneliness of elderly people emerged across the papers: loneliness-an issue for wellbeing in life after retirement; the effects of gardening and plants on loneliness; gardening - a therapeutic tool to combat loneliness; elderly's loneliness during the pandemic and home gardening; and national and international initiatives to decrease loneliness in the elderly population. The review found a significant gap in literature directly connecting loneliness in the elderly with gardening activities for happy and healthy life ageing. The review found that there is a limited number of literatures on the loneliness situation of elderly people during the pandemic, where gardening plays a vital role to reduce the psychological problem while maintaining the social distancing and isolation.
\end{abstract}

Keywords: social life, senior citizen, therapeutic effects, wellbeing, Nepal.

\section{Introduction}

Worldwide population ageing is considered one of the most important demographic phenomena, as the elderly population is increasing almost all around the world. The gradual process of ageing is a universal and multidimensional phenomenon, leading all individuals through life in its course from birth to death. Ageing brings about many morphological and physiological and social changes (Dangal \& Singh, 2019), which affect often adversely to the social life of senior citizens (Panda \& Nayak, 2012). For older people who are living in their own homes, it is extremely important to understand how to help them continue to live healthy, fulfilling lives. The prevalence of loneliness is quite common among the older population (ranging between $28 \%$ and $63 \%$ ), enough for it to be recognized as a serious public health issue of human beings in later life (Pimlott, 2018).

The review found a significant gap in the literature directly connecting loneliness in the elderly with gardening activities; however, this study aims to explore the issue of loneliness in

(C) Authors. Terms and conditions of Creative Commons Attribution 4.0 International (CC BY 4.0) apply. Correspondence: Megh Raj Dangal, Kathmandu University, School of Arts, Kathmandu, NEPAL. E-mail: megh@ku.edu.np. 
old age along with the therapeutic effect of gardening for healthy ageing. This study provides a thematic analysis of loneliness in older people after retirement and their wellbeing.

Human life is divided and understood at different stages such as infancy, babyhood, childhood, adolescence, adulthood and old age (Nayak \& Panda, 2012). Humans are social creatures and no most people are unable to live without the social web, but modernization has brought about more feelings of isolation and "the age of loneliness". In an era characterized by population ageing, more and more people are living longer and alone. Thus, loneliness among senior citizens has become a social issue in contemporary societies (Guo, 2009). Yet, the study of loneliness itself comes with its own problems. The knowledge of the effects of loneliness is complicated by studies which measure constructs that are similar to loneliness or may include aspects of loneliness such as "being alone", lack of closeness", lack of confiding relationships and social isolation. It is broadly agreed that loneliness is not directly the result of social isolation or living alone but it is the absence of healthy relationships with other people. Loneliness is defined as the negative outcome of a cognitive evaluation of a discrepancy between the quality and quantity of existing relationships and relationship standards (Singh \& Kiran, 2013).

During ageing life or life after retirement, people tend to gravitate towards different hobbies and pastime activities like playing card games, gardening, reading, travelling, social work, social gatherings etc. to reduce loneliness or to cope with retirement. Among these activities, the elderly people who get involved in gardening do so out of pure interest without fully understanding the range of social, economic and health benefits of this activity. Currently, there is a lack of scientific studies conducted on the effects of gardening on elderly health and well-being of people, especially on an individual level. Available studies are mainly focused on hospital patients suffering from ailments like dementia, Alzheimer's, and mental retardation, among others. Regarding elderly people who are engaged in the horticultural activities by their own knowledge and interest at the individual household level, it is difficult to find research about the impact of gardening on their wellbeing from social, economic, cultural and health perspectives.

Most elderly people express the desire to die in peace before having to depend fully on the next generation for minor issues and daily life requirements, expectations which form a part of 'functionally' able ageing. Hence, functional stability and independence from core criteria of happy and healthy ageing (Chalise, 2006). The World Health Organization (WHO) has defined healthy ageing as a process of maintaining functional ability to enable wellbeing in older age. The time frame of 2020 to 2030 has also been named "The Decade of healthy Ageing". According to a demographic projection, the number of people age 60 years and older will be $34 \%$ higher by the end of this decade (2020-2030), increasing from 1 billion to 1.4 billion. By 2050, the global population of older people will have more than doubled to 2.1 billion (WHO, 2020). Similarly, in developing countries, the number of people aged 60 years and older will increase most rapidly from 652 million in 2017 to 1.7 billion in 2050 (Kandel, 2020). Along with other nations, Nepal is also experiencing a demographic shift towards an ageing population, presenting a challenging situation in the context of wellbeing of senior citizens (Chalise, 2006).

\section{Loneliness- an issue for wellbeing in life after retirement}

Loneliness is generally defined as "an emotional state in which a person experiences a powerful feeling of emptiness and isolation." It is a state where a person feels isolated, abandoned, rejected and neglected by the near and dear ones or the societies (Nayak \& Panda, 2012). Loneliness can greatly impact the well-being of elderly people as it is a cause of emotional distress and is linked to a variety of health problems in older individuals. Gender, social and cultural factors influence the experiences of loneliness in older people (Singh \& Kiran, 2013). 
Human beings have an intrinsic need for social connections and an engagement with the social environment. Lack of or unhealthy social relationships lead to feelings of isolation and loneliness in older people (Brownie \& Horstmanshof, 2011). In 2017, The UK Government commission issued the results of a year-long investigation which studied the prevalence of loneliness in the UK. Accordingly, 9 million Britons or $14 \%$ of the population was reported to be suffering from loneliness. Among the more vulnerable, such as the elderly and those living with disabilities, the rates are much higher (Pimlott, 2018). Loneliness and resulting health issues became prominent enough to prompt former British Prime Minister Theresa May to appoint a "Loneliness Minister" in January 2018 (Paudel, 2020).

Traditionally, Nepalese society had joint and extended family structures and the society had norms and values of showing respect, looking after, and caring for the elderly parents or grandparents of their family. They were also provided respect in the society in different ways. Nowadays, due to many reasons like nuclear family, migration from rural to urban or abroad, the trend towards modernization, rise in individualism and increasing technology (easy access to technical devices), elderly people are suffering from increased disrespect and loneliness.

Although it is not discussed often, it is a commonly accepted belief that with old age comes loneliness. Loneliness in the current age may even be termed as an "epidemic." Although Nepali society has traditionally been structured to provide a calming touch to its seniors though its close-knit circles of friends and family, this characteristic is now in decline. Family touch is quite valued in Nepal, and its absence becomes a glaring and major cause of sorrow especially in old age (Paudel, 2020).

Reviewing the available data, most retired people suffer mental stress immediately after retirement because they are used to an active working life and have no way to engage themselves without their job. This is especially the case in the retired male population because most males in Nepalese societies are not habituated or interested in doing household work.

\section{The effects of gardening and Plants on loneliness}

Plants have been present in history since the beginning of life on this planet and play a very crucial role in the life of every human being. Home gardening is a branch of horticulture. Over the past few decades, horticulture has been used as a suitable treatment for the elderly in long term care. The word originates from the roots hortus, meaning "garden" and culture, referring to the development, improvement or modification of the mind, feelings, interests, behaviors, tastes, ideas, customs, skills, art etc. Here specifically, it refers to "soil cultivation". In horticulture treatment programs, plants and home gardening are used to improve the mind, body and morale of the people involved. This may be the new approach to promoting mental, social, and cognitive functioning of the elderly. It is found that engaging in outdoor surroundings benefit older people in three main ways: participation in outdoor physical activities, improved mental health and function, and social interaction with others (Pouya, 2018).

The reciprocal relationship between humans and plants through gardening can knowingly and unknowingly serve therapeutic benefits to promote wellbeing (especially hedonic and eudaimonic wellbeing) (Rae, 2013). Additionally, many studies have also found that a physically active lifestyle reduces the risk of developing cardiovascular disease, obesity, osteoporosis, dementia, several forms of cancer and depression in health-conscious people who are residing in urban areas. Hence, it is important to find ways to keep people physically active even after retirement (Rappe, 2005). Due to limited recreational spaces at home, lack of public facilities like parks and the unavailability of elderly people focused recreation centers in the urban areas of developing countries like Nepal for exercise or interactions with community people, most retired people have turned to gardening at their homes a pastime. 
Typically, a home garden is a kind of integrated cropping pattern in the urban areas. In most urban settlements, families have been doing subsistence home gardening with a combination of vegetables, spices (turmeric, ginger, garlic, chili, coriander, rosemary, oregano etc.) and at least one or two fruit varieties (such as lemon, guava, etc.) necessary for everyday for cooking.

\section{Gardening - A therapeutic tool to combat loneliness}

Plants play a very important role in the life of every individual. They have been present in human history since the beginning of its development. The effectiveness of garden and plants were noted when used as therapeutic tools in the $1^{\text {st }}$ half of $20^{\text {th }}$ century on the $1^{\text {st }}$ and $2^{\text {nd }}$ world war veterans who suffered from stress discover and post-camp asthenia (Gulczynska, Horticultural Therapy and Gardening-Comparison of Dimension, 2019). Seniors especially can benefit from interacting with nature through horticultural activities. Planting and enjoying the results of a therapeutic garden is considered one of the many proven holistic treatments for those in need of rehabilitation and healing, stimulation, social engagement and more. Seniors experience remarkable benefits from connecting to the earth. The practice of planting flowers and vegetables, getting their hands dirty and watching their efforts turn into beautiful results gives them a sense of empowerment that too often vanishes with age. According to Haas et al. (1998), "With older adults, all types of horticultural activities from planting and weeding to making a flower arrangement can be used in therapy".

The therapeutic garden environment has been documented since ancient times. The first person to document the use of horticulture as therapy was Dr. Benjamin Rush, according to the American Horticultural Therapy Association-AHTA. Recognized as the "Father of American Psychiatry", he reported the positive effects of gardening for individuals with mental illnesses. Later, in the 1940 s and 1950s, the practice was used in the rehabilitation of war veterans and from the treatment of different types of diagnosis (AHTA, 2020). A famous British gardener designer Gertrude Jekyll ( $19^{\text {th }} / 20^{\text {th }}$ century) wrote that a garden is a miraculous teacher of patience; diligence, thrift and most of all- limitless generosity (Gulczynska, HT and Gardening-Composition of Dimension, 2019).

Gardening is a popular pastime in the United States, worth investigating because of its potential for important effects on the individual as well as on the ecosystem. A 2003 survey by the National Gardening Association found that it is a popular activity among Americans, where 78\% or 84 million US households participate in some do-it-yourself lawn and garden activities. It is one of the principal ways in which they experience nature (Clayton, 2007).

Plants have positive impacts on the functional and cognitive abilities of elderly people, affecting their psyche through both observation of gardens as well as involvement in horticulture activities. Studies have shown that exposure to plants can create positive emotions and reduce mental stress as well as increase the emotional and cognitive health of the elderly. Horticultural activities allow reciprocal relationships with nature and other people; where the elderly are not only recipients of care but can give nurturing and valuable things to others (Rappe, 2005).

Gardening practices can describe more generalized aspects of the social identity as well; traditionally, well- kept lawns signified higher social status. By serving as a locus for social interaction, gardening can not only reflect, but also create social connection (Clayton, 2007).

Activities can be done indoors, outdoors or even virtual, with flowers and plants used as supporting instruments to make the population feel better, including the situation experienced by the period seclusion (Reis, Reis \& Nascimento, 2020). The home garden is a small part of the farming system which is usually located around the family home to supply fresh food and herbs. 
5. Elderly's loneliness during the pandemic and home gardening

Social workers and other gerontological scholars have increasingly voiced concern about loneliness (subjective perception of lack of meaningful relationships) and social isolation (social engagement and contacts) among older adults. In 2015, one of the twelve Grand Challenges for Social Work was to "Eradicate Social Isolation". By 2017, the term "loneliness epidemic" was used by the U.S. Surgeon General Vivek Murthy proclaimed that the adult population was suffering a global epidemic. The COVID-19 pandemic has brought even more attention to the issues of social isolation and loneliness (Dangal \& Bajracharya, 2020) for all ages, particularly older adults who are the most vulnerable, at-risk segment of the population (Berg-Weger \& Morley, 2019). Older people's sense of fear, isolation and loneliness has been recognized to be an emotional feature of COVID-19. Social isolation refers to the lack of physical contact with, or separation from family, friends, and social networks as well as the lack of involvement in outside activities. During the COVID-19 pandemic, where there are many social restrictions (Dangal \& Maharjan, 2021) applied especially to elderly people, gardening can be a safe and extremely beneficial activity for them to engage in.

Social isolation, one of the recommended practices to curb the spread of the disease, can lead to the development of several problems such as loneliness, depression, stress, and apathy. However, practices associated with the cultivation and contemplation of flowers and ornamental plants can be an option to aid in the care for the mental health of the population.

Home gardening has long been used to satisfy different types of human needs on a daily basis. Connecting with nature is crucial to the development process and, in times of social isolation, limiting access to green areas tends to aggravate the damage to people's physical and mental health. Home gardening associated vegetables and ornamental plants (indoor/outdoor) for aesthetic value under the horticultural practices particularly contribute to the requirement in nutrition, vitamins, calories, oxygen and medicinal herbs as well as cultural ecosystem for human well-being (Reis, Reis \& Nascimento, 2020).

During the pandemic, all social relationships have taken a toll with restrictions being applied to all events including parties, festivals, meetings, conferences, wedding, sports events, get-togethers, and picnics etc. There have been difficulties in affording materials even for middle and high-income people due to barriers internationally in production and distribution. The rush to buy food materials again poses safety hazards during the global pandemic. The COVID-19 pandemic has disrupted the food supply chain in urban areas due to lengthy lockdowns. Those infected with the disease were forced to self-isolate in their own homes. During this pandemic, as senior citizens are highly vulnerable, they have the most restrictions in social engagement.

Logistically, a home garden provides easy day to day access to fresh vegetables, fruits, spices, ornamental (indoor \& outdoor plants) and herbal plants. In the context of Nepal, a home garden is an integrated part of the landscape and culture for centuries but due to limited land and busy schedule in the life of urban people have limited the scope of home gardens in leisure time. At this time, home gardening has an increased significance as a way to support household food security, utilize time, ensure and enhance family bonds, contribute to mental health, health safety and the overall contribution to well-being of the people while creating green and healthy spaces (Dissanayake \& Dilini, 2020). 


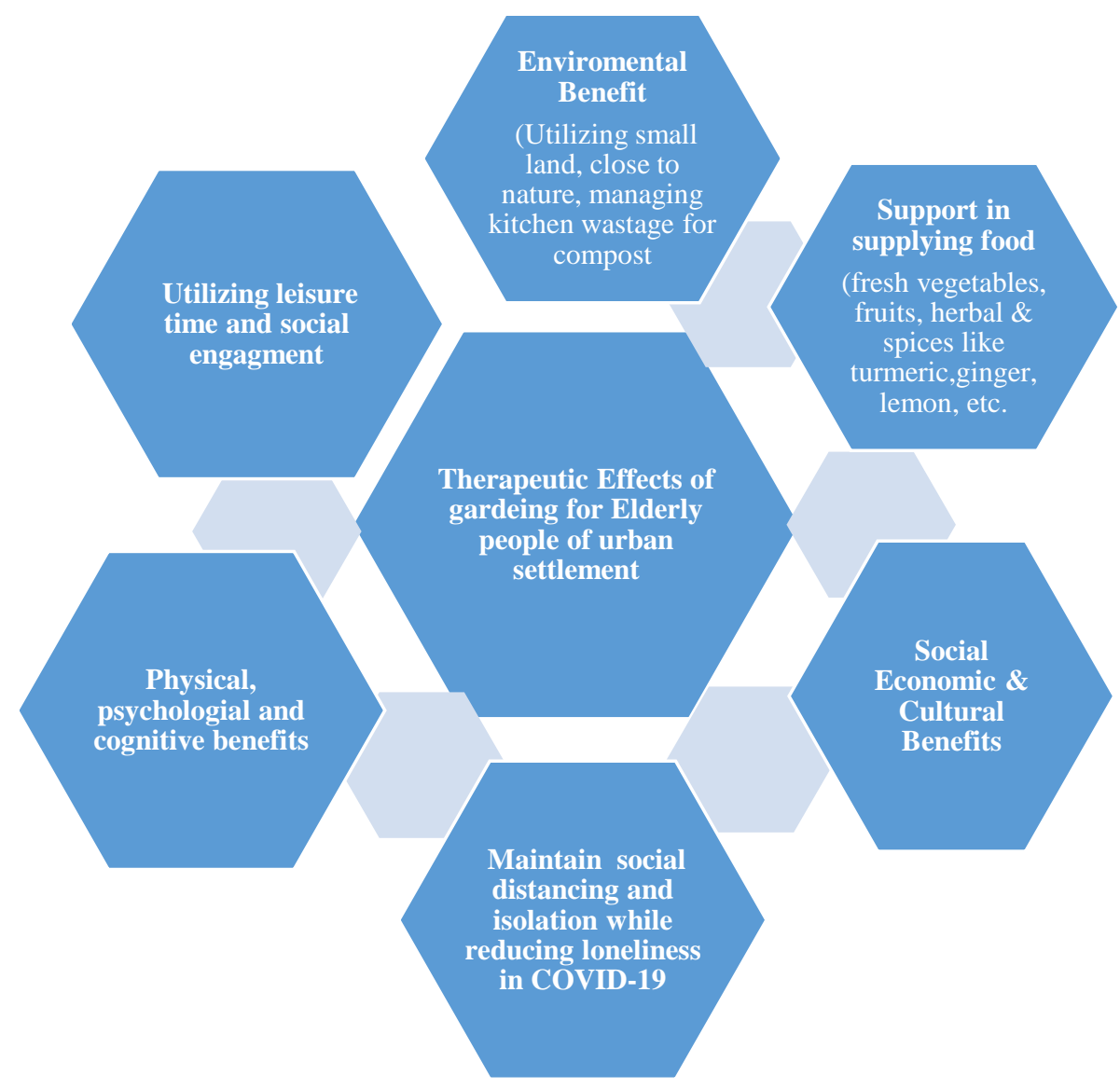

Figure 1. Review analysis from various literature regarding loneliness of elderly citizens and therapeutic effects of gardening

6. National and international initiatives to decrease loneliness in elderly population

The issues of social isolation and loneliness in older people are being brought more into the forefront of both national and international health and social care policies and campaigns, and are increasingly recognizing the importance of tackling social isolation and loneliness among older people. In 2011, The Campaign of End Loneliness was run in 2011 as a network of national, regional, and local organizations working together to make sure loneliness is treated as a public health priority. Similarly, the New Zealand government has committed to a vision of positive ageing principles which promote community participation and prevent social isolation (Clare, Geldenhuys \& Gott, 2018).

The fact that solitary confinement is used as a form of punishment and torture shows how distressing social and isolation and loneliness is to humans. Yet, loneliness is found to be on the rise in most nations including the US, Germany, Australia and the UK, suggesting that we are facing loneliness (Holt-Lunstad, 2018).

The concern for the study of the elderly increased following the adoption of the International Plan of Action on Ageing by the United Nations (UN) in Vienna, Austria in 1982. Twenty years later, an action plan was outlined during the Second World Assembly on Ageing held in Madrid, Spain which targeted to increase awareness of ageing issues at national and regional levels, and develop concrete plans of action for ageing. However, advances have been few and far 
between in much of the developed world and virtually overlooked in developing countries like Nepal (Bhandari, 2075). Following the Madrid Plan of Action, the Government of Nepal (GoN) has formulated a National plan of Action 2062 (2005) for senior citizens, developed various aspects such as economic and social security, health and nutrition, participation and involvement, education and entertainment and legal condition and reforms. It identifies the elderly as one of its main target groups (Country Report/Nepal, 2007).

As a member state of the UN and as a signature country of the Universal Declaration of Human Rights (UDHR) and various other important international conventions, Nepal has expressed international commitment to develop social security services in line with constitutional provisions of the country. In response to tackling ageing issues and addressing their needs and challenges, the government of Nepal has formulated national policies and security programs for senior citizens and has committed itself to various regional and international conventions to promote healthy ageing (Bhandari, 2075).

\section{Conclusion}

Loneliness is often considered a major problem for the increasing older population. While the study of loneliness of elderly people is a multidimensional area covering several issues and problems, this review focused on how gardening can be used by the elderly in combating loneliness and maintaining a healthy and happy later life. Plants play a very important role in physical, mental, and social aspects of human life. Since gardening activities are regarded as therapeutic for people with health problems and especially helpful in dealing with loneliness in later life, implementation of gardens and indoor plants is recommended in their homes. The elderly generally has limited possibilities to promote wellbeing of their own health, and there are many national and international policies and program interventions to promote the wellbeing of elderly people to reduce social isolation and loneliness. Similarly, the COVID-19 pandemic was also a great challenge for all countries as the elderly faced greater social isolations and loneliness during this period. During this time, gardening was the most effective therapeutic tool to reduce risks and vulnerabilities pertaining to elderly health.

Research studies of loneliness in elderly population and its relation to gardening is still in infancy stages in Nepal. This review study concluded that human-plants interactions through gardening brings about six main types of therapeutic effects for the ageing process i.e. environmental benefits, support in supplying food, social economic and cultural benefits, utilization of leisure time, social engagement and maintenance of social distancing and isolation during pandemics such as COVID-19.

\section{Acknowledgements}

This research did not receive any specific grant from funding agencies in the public commercial, or not-for-profit sectors.

The authors declare no competing interests. 
G. Khadka \& M. R. Dangal - Social Life of Senior Citizens: A Review of Therapeutic Effects...

\section{References}

AHTA (2020). History of horticultural therapy. American Horticultural Therapeutic Association. https://www.ahta.org/.

Berg-Weger, M., \& Morley, J. (2019). Loneliness and social isolation in older adults during the covid: Implications for gerontological social work. $J$ Nutr Health Ageing, 456-458. https://link.springer.com/content/pdf/10.1007/s12603-020-1366-8.pdf.

Bhandari, K. (2075). Social security system of elderly population in Nepal. NUTA JOUNAL, 18-24. https://www.nepjol.info/index.php/nutaj/article/view/23223.

Brownie, S., \& Horstmanshof, L. (2011). The management of loneliness in aged care residents: An important therapeutic garget for gerontological nursing. Elsevier-Geriatric Nursing, 318-325. https://www.sciencedirect.com/science/article/pii/So197457211003375.

Callow, D. D. (2020). The mental health benefit of physical activity in older adults survive the COVID-19 pandemic. The American Journal of Geriatric Psychiatry, 1046-1057. https://doi.org/10.1016/jijagp.2020.06.024

Chalise, H. N. (2006). Demographic situation of population ageing in Nepal. Kathmandu University Medical Journal, 4 3(15), 354-362. http://www.kumj.com.np/issue/15/354-362.pdf.

Clare, G., Geldenhuys, G., \& Gott, M. (2018, June 9). Interventions to reduce social isolation and loneliness among older people. Health and Social Care in the Community, 147-157. https://onlinelibrary.wiley.com/doi/pdf/10.1111/hsc.12367.

Clayton, S. (2007). Domesticated nature: Motivations for gardening and perceptions of environmental impact. Journal of Environmental Psychology, 10.

https://www.sciencedirect.com/science/article/pii/So272494407000485.

Country Report/Nepal (2007). Economic and social commission for Asia and the Pacific. https://www.unescap.org/sites/default/files/No.\%2044\%20PB_fin\%20inclusion_12July16.p df.

Dangal, M. R., \& Bajracharya, L. S. (2020). Students anxiety experiences during COVID-19 in Nepal. Kathmandu University Medical Journal, 7o(2), 53-57. http://www.kumj.com.np/issue/70/53-57.pdf.

Dangal, M. R., \& Maharjan, R. (2021) Health problems experienced in online learning during COVID-19 in Nepali Universities. International Journal of Online Graduate Education, 4(1), 1-14. https://doi.org/10.5281/zenodo.4509020

Dangal, M. R., \& Singh, A. R. (2019). Girls bullying in Nepali schools: A perception study on awareness level of verbal and non-verbal bullying among teenagers. Open Journal for Psychological Research, 4(1), 1-16. https://doi.org/10.32591/coas.ojpr.0401.01001d

Daoust, J. F. (2020). Elderly people and responses to COVID-19 in 27 countries. PLOS ONE. https://doi.org/10.1371/journal.pone.0235590

Dissanayake, L., \& Dilini, S. (2020). COVID-19 outbreak and urban green space food security and quality of life: Case of urban home gardens in Kandy, Sri Lanka. Scientific Research Open Access, 13. https://www.scirp.org/html/13-1763830_102981.htm.

Girija, P., \& Sivan, N. (2020). Ayurvedic treatment of COVID-19/SARS-CoV-2: A case report. https://www.sciencedirect.com/science/article/pii/So975947620300425.

Gulczynska, A. (2019). Horticultural therapy and gardening - Comparison of dimension. Research Gate, 347-355. https://doi.org/10.13140/RG.2.2.14049.97129

Gulczynska, A. (2019). HT and gardening - Composition of dimension. http://hdl.handle.net/10593/23719. 
Guo, z. (2009). Loneliness of older adults in rural China. Gerontology Institute. https://scholarworks.gsu.edu/cgi/viewcontent.cgi?article=1016\&context=gerontology_these s.

Holt-Lunstad, J. (2018). The potential public health relevance of social isolation and loneliness: Prevalence, epidemiology and risk factors. Public Policy and Ageing Report. https://academic.oup.com/ppar/article-abstract/27/4/127/4782506.

Lal, R. (2020). Home gardening and urban agriculture for advancing food and nutritional security in response to the COVID-19 pandemic. International Society for Plant Pathology and Springer Nature B.V 202O. https://doi/10.1007/s12571-020-01058-3

Nayak, L. M., \& Panda, B. L. (2012). National and international approaches to reduce vulnerability among elderly in India. Indian Streams Research Journal, 1-4. https://www.academia.edu/download/33019165/elderly.pdf.

Panda, B., \& Nayak, L. M. (2012). National and international approaches to reduce vulnerability among elderly in India. Indian Streams Research Journal, 1-4. https://www.academia.edu/download/33019165/elderly.pdf.

Paudel, A. (2020). The Annapurna Express. https://theannapurnaexpress.com/news/loneliness-amongthe-elderly-a-growing-social-problem-2296.

Pimlott, N. (2018). The ministry of loneliness. Canadian family physician. Retrieved from https://www.cfp.ca/content/cfp/64/3/166.full-text.pdf.

Pouya, S. (2018). The importance of horticulture therapy and gardening for older adults in nurshing home. https://dergipark.org.tr/en/pub/sanattasarim/issue/43408/529734.

Rappe, E. (2005). The influence of a green environment and horticultural activities on the subjective wellbeing of the elderly living in long-term care. https://helda.helsinki.fi/bitstream/handle/10138/20703/theinflu.pdf;sequence=1 .

Reis, S., Reis, M., \& Nascimento, A. (2020). Pandemic, social isolation and the importance of peopleplant-plant interation. SciELO. https://www.scielo.br/scielo.php?pid=S2447536X2020000300399\&script=sci_arttext.

Singh, B., \& Kiran, U. (2013). Loneliness among elderly women. International Journal of Humanities \& Social Invention, 1-6. https://www.researchgate.net/profile/UV_Kiran2/publication/236161239_Loneliness_amo ng_elderly_women/links/oob495180e38020628000000.pdf.

WHO (2020). COVID-19 and the Decade of Healthy Ageing. https://www.who.int/docs/defaultsource/decade-of-healthy-ageing/decade-connection-series---covid-19en.pdf?sfvrsn=d3f887bo_7.

WHO (2020). Ageing. https://www.who.int/health-topics/ageing\#tab=tab_1.

WHO (2020). Constitution. https://www.who.int/about/who-we-are/constitution. 
G. Khadka \& M. R. Dangal - Social Life of Senior Citizens: A Review of Therapeutic Effects...

C O A $\mathbf{s}$ 